\title{
T $\beta$ RII Regulates the Proliferation of Metanephric Mesenchyme Cells through Six2 In Vitro
}

\author{
Zhaomin Mao ${ }^{\dagger}$, Zhongshi Lyu ${ }^{\dagger}$, Liyuan Huang, Qin Zhou and Yaguang Weng * \\ The M.O.E. Key Laboratory of Laboratory Medical Diagnostics, the College of Laboratory Medicine, \\ Chongqing Medical University, Chongqing 400016, China; mao1204086118@163.com (Z.M.); \\ 284003771@163.com (Z.L.); lyhuang0603@sina.com (L.H.); zhouqin@cqmu.edu.cn (Q.Z.) \\ * Correspondence: yaguangweng@126.com; Tel.: +86-137-0831-6932 \\ + These authors contributed equally to this work.
}

Academic Editor: Gregor Drummen

Received: 12 February 2017; Accepted: 11 April 2017; Published: 18 April 2017

\begin{abstract}
The transforming growth factor- $\beta$ (TGF $\beta$ ) family signaling pathways play an important role in regulatory cellular networks and exert specific effects on developmental programs during embryo development. However, the function of TGF $\beta$ signaling pathways on the early kidney development remains unclear. In this work, we aim to detect the underlying role of TGF $\beta$ type II receptor (T $\beta$ RII) in vitro, which has a similar expression pattern as the crucial regulator Six2 during early kidney development. Firstly, the 5-ethynyl-2'-deoxyuridine (EdU) assay showed knock down of TRRII significantly decreased the proliferation ratio of metanephric mesenchyme (MM) cells. Additionally, real-time Polymerase Chain Reaction (PCR) and Western blot together with immunofluorescence determined that the mRNA and protein levels of Six 2 declined after T $\beta R I I$ knock down. Also, Six 2 was observed to be able to partially rescue the proliferation phenotype caused by the depletion of $T \beta R I I$. Moreover, bioinformatics analysis and luciferase assay indicated Smad3 could transcriptionally target Six2. Further, the EdU assay showed that Smad3 could also rescue the inhibition of proliferation caused by the knock down of T $\beta R I I$. Taken together, these findings delineate the important function of the TGF $\beta$ signaling pathway in the early development of kidney and TRRII was shown to be able to promote the expression of Six 2 through Smad3 mediating transcriptional regulation and in turn activate the proliferation of MM cells.
\end{abstract}

Keywords: T $\beta$ RII; Six2; Smad3; kidney development; proliferation

\section{Introduction}

The transforming growth factor- $\beta$ (TGF $\beta$ ) family signaling pathways are composed of various closely related proteins which share some structural homology but have separate receptors and take part in different functions; for example, activated TGF $\beta$ ligands bind to type 2 TGF $\beta$ receptor, which is a kinase, which recruits, phosphorylates, and activates the type 1 receptor that then phosphorylates receptor-regulated Smads to bind the co-Smads, acting as transcriptional factors [1]. This leads to the activation of different downstream target genes that function in many cellular processes, including proliferation, differentiation, apoptosis, cell growth, and other cellular functions both in embryo and adult organism $[1,2]$.

During kidney development, there is a balance between consumption (differentiation) and self-renewal (proliferation) of Six 2 positive mesenchymal nephron progenitor-cells (cap mesenchyme cells) in order to form the full complement of nephrons and nephron endowment. The former is instructed by the mutual inductive interactions from ureteric bud cells [3-5], which secrete Wnt9b, activating a canonical Wnt- $\beta$-catenin signaling pathway in cap mesenchyme cells [6-9]. The canonical Wnt pathway leads to the degradation of GSK-3 $\beta / \mathrm{CK} 1 \alpha / \mathrm{AXIN} 2 /$ Adenomatous polyposis coli 
(APC) complex and the translocation of cytosolic $\beta$-catenin to nucleus, promoting extensive target genes including Wnt4 and Fgf8. Wnt4 and $F g f 8$ expressed in the cap mesenchyme cells then trigger their differentiation (mesenchymal-to-epithelial transition (MET)) into an epithelial structure-renal vesicle $[10,11]$, which subsequently gives rise to a single nephron. The development of nephron relies on Six2, with high expression in cap mesenchyme cells and low expression in renal vesicles, and is the crucial transcriptional regulator for promoting the proliferation of cap mesenchyme cells and inhibiting Wnt4 and Fgf8-mediated differentiation of these cells. Six 2 knockout mice display ectopic differentiation, depletion of metanephric mesenchyme cells, and kidney hypoplasia and dysplasia $[5,12]$.

Though Six2 serves an essential function in nephron progenitor cells maintenance during early kidney development, little is known about its underlying upstream regulation and related signal pathway. In this study, we showed that TGF $\beta$ type II receptor (T $\beta$ RII) has a similar expression pattern with Six 2 during kidney development, in line with prior RNA-sequencing research work [13] documenting that T $\beta$ RII possesses a higher expression in the cap mesenchyme cells and a lower expression in renal vesicles. T $\beta R I I$ knock-down in metanephric mesenchyme (MM) cell line prevented the proliferation of metanephric mesenchyme cells and the phosphorylation of its downstream transcription factor Smad 3 as well as the expression of Six 2 at mRNA and protein levels. Overexpression of Six 2 was able to rescue the T $\beta R I I$ depletion-caused inhibition of proliferation phenotype. In addition, the TGF $\beta$ ligands activated the phosphorylation of Smad3 and enhanced the expression of Six2, while the inhibition of the TGF- $\beta$ signal pathway by SB431542 decreased the expression of Six 2 and suppressed the proliferation of $\mathrm{mK} 3$ cells. Further analysis proved that Smad3, activated by the TGF- $\beta$ signaling pathway, transcriptionally regulated Six 2 and rescued the proliferation phenotype caused by the knockdown of T $\beta R I I$. Our research revealed the functional effect of T $\beta R I I$ in metanephric mesenchyme cells and elaborated its specific molecular mechanism regarding Six2 up-regulation during kidney development.

\section{Results}

\subsection{TßRII Promoted the Proliferation Rate of Metanephric Mesenchyme (MM) Cells}

To explore whether T $\beta$ RII was involved in early kidney development, we first detected the expression pattern of T $\beta$ RII during early kidney development from E11.5 to E14.5. We found that $T \beta R I I$ exerted a relatively higher expression in E11.5 embryo kidney and a relatively lower expression after E11.5, which was in line with the RNA-sequence data [13] and indicated an important role of T $\beta R I I$ during early kidney development. We next transfected the siCTL (negative control with

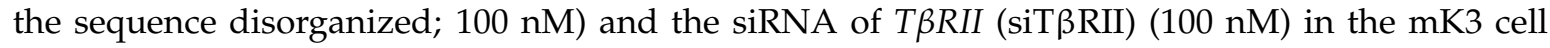
lines [14]. Then we performed the real-time Polymerase Chain Reaction (PCR) to detect the expression

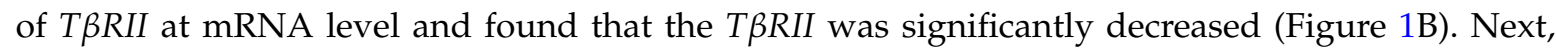
a 5-ethynyl-2'-deoxyuridine (EdU) assay was carried out to identify the proliferation rate of $\mathrm{mK} 3$ cells after the transfection, and the results showed that the proliferation rate was reduced by nearly half (Figure 1C,D). These data indicated that T $\beta$ RII could promote the proliferation of MM cells.

\subsection{T $\beta$ RII Increased the Expression of Six2}

Next, we explored the possible mechanism relating to the proliferation after the knockdown of $T \beta R I I$. In order to investigate this problem, we first detected the expression pattern of Six2, which is one of the most classical regulators of MM proliferation, during early kidney development and found that the data was in line with the RNA-sequence data that showed a higher expression of Six2 and T $\beta R I I$ in E11.5 embryo kidney and a lower expression of them in E12.5 embryo kidney (Figure 2A). After the discovery of the similar expression tendency, we wanted to explore the interrelationship between the data. Therefore, we transfected the siRNA $(100 \mathrm{nM})$ into $\mathrm{mK} 3$ cells and first detected the expression of Six 2 by real-time PCR. The result demonstrated that the mRNA level of Six 2 decreased by more 
than $50 \%$ (Figure 2B). After the knock down of T $\beta R I I$, the protein level of T $\beta R I I$, Six 2, and p-Smad3 were significantly decreased, while the expression of T $\beta$ RI and Smad3 did not exhibit obvious change (Figure 2C). In line with the results above, the immunofluorescence also demonstrated a remarkable decline after the knock down of T $\beta R I I$ in mK3 cells (Figure 2D). These data suggested that T $\beta$ RII could up-regulate the expression of Six 2 both at mRNA level and protein level.

A

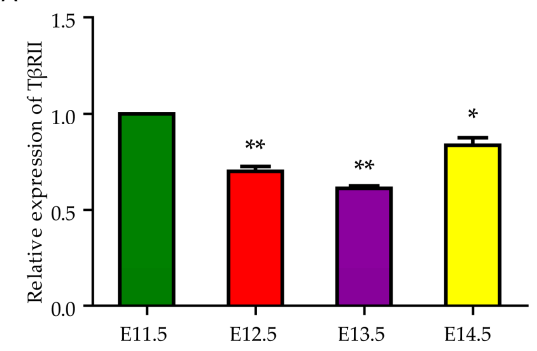

B

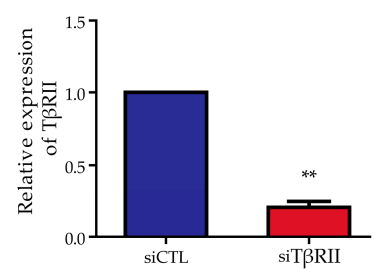

C
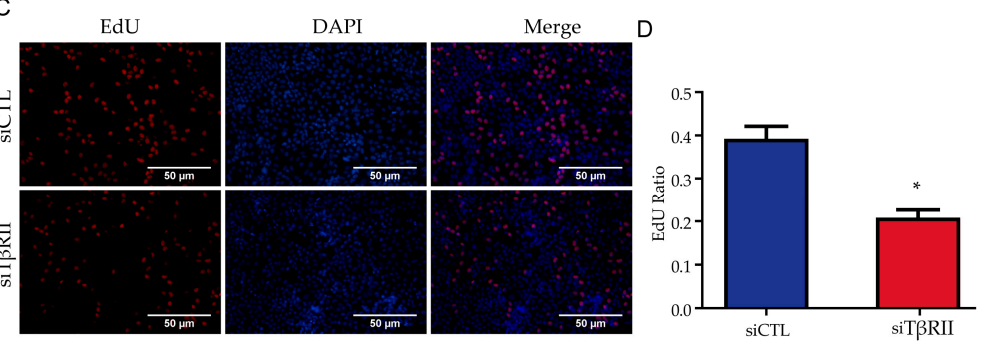

Figure 1. TGF $\beta$ type II receptor (T $\beta R I I)$ promotes the proliferation of $\mathrm{mK} 3$ cells. (A) The expression pattern of T $\beta R I I$ at mRNA level of embryo kidney from E11.5 to E14.5; (B) The mRNA level of T $\beta R I I$ in $\mathrm{mK} 3$ cells after the treatment of siT $\beta$ RII; (C) The proliferation rate of $\mathrm{mK} 3$ cells after the transfection of siTßRII; (D) Histogram shows the quantitative analysis of the 5-ethynyl-2'-deoxyuridine (EdU) assay. All data are displayed as means \pm Standard Deviation (SD) from three independent experiments, ${ }^{*} p<0.05,{ }^{* *} p<0.01$.

A

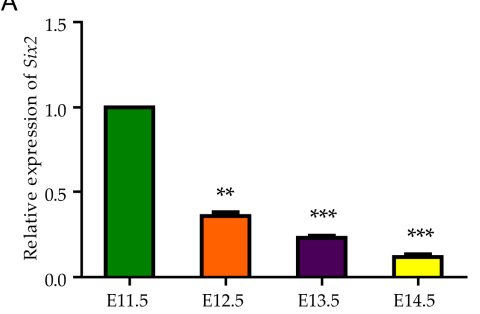

C

D
B

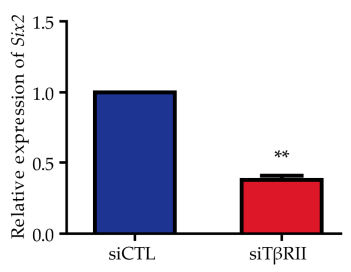

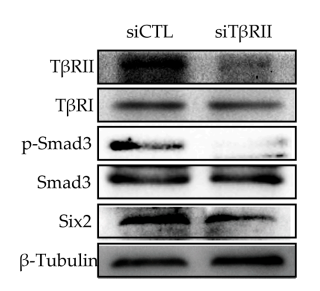
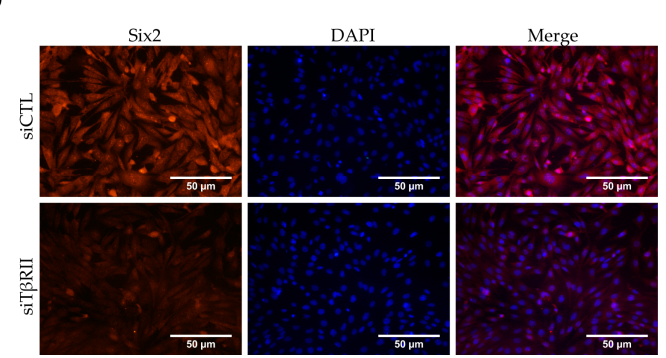

Figure 2. TRRII increases the expression of Six 2 in $\mathrm{mK} 3$ cells. (A) The expression pattern of Six2 at mRNA level of embryo kidney from E11.5 to E14.5; (B) The mRNA level of Six2 in mK3 cells after the treatment of siTßRII; (C) The protein level of Six2, p-Smad3, Smad3, and T $\beta$ RI in mK3 cells after the treatment of siT $\beta$ RII; (D) The immunofluorescence of Six 2 after the treatment of siT $\beta$ RII. All data are displayed as means \pm SD from three independent experiments, ${ }^{* *} p<0.01,{ }^{* * *} p<0.001$. 


\subsection{Overexpression of Six2 Can Rescue the Proliferation of MM Cells Induced by TRRII Deficiency}

To further explore the important function of Six 2 on the inhibition of proliferation caused by the knockdown of T $\beta R I I$, we co-transfected siT $\beta$ RII with Six2 expression vector (pcDNA3.1(+)Six2) into $\mathrm{mK} 3$ cells, and subsequently performed an EdU assay. As shown in Figure 3A,B, compared with the mK3 cells transfected with siT $\beta$ RII and the control vector (pcDNA3.1(+)), co-transfection of siT $\beta$ RII and pcDNA3.1(+)Six2 can partially relieve the inhibited proliferation level. Therefore, Six2 overexpression could partially rescue the suppressed cell proliferation caused by deficiency of T $\beta$ RII.

A

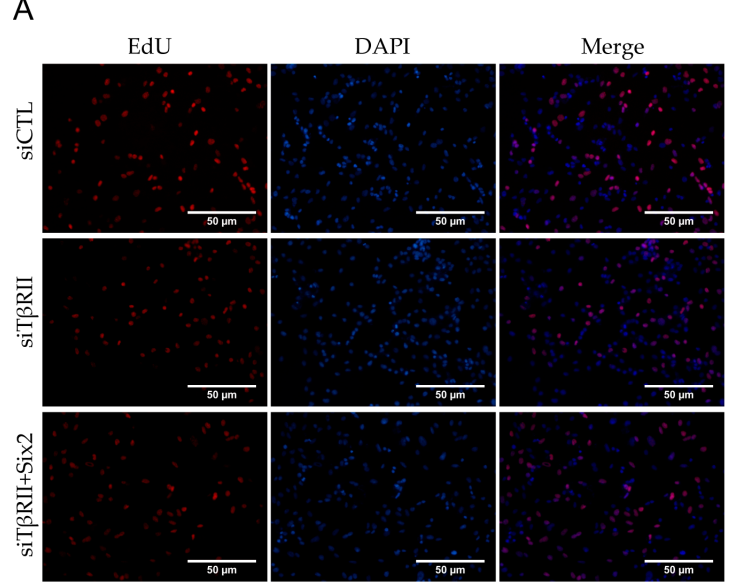

B

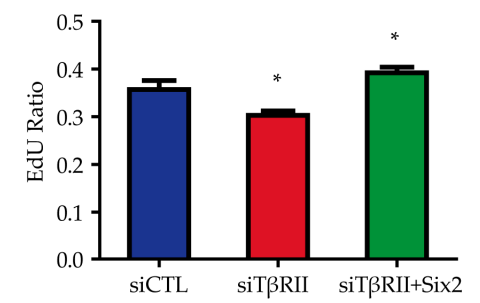

Figure 3. Six2 rescues the proliferation phenotype. (A) The proliferation rate of $\mathrm{mK} 3$ cells after the transfection of siT $\beta$ RII and the co-transfection of Six2; (B) Histogram shows the quantitative analysis of the EdU assay above. All data are displayed as means \pm SD from three independent experiments, $* p<0.05$.

\subsection{Smad3 Can Transcriptionally Regulate Six2 and Partially Rescue the Proliferation Phenotype}

To further confirm the function of the TGF $\beta$ signaling pathway towards Six2, we stimulated $\mathrm{mK} 3$ cells with TGF $\beta$ I factor for 24 and $48 \mathrm{~h}$, and the results demonstrated a gradual increase of Six 2 both at mRNA and protein levels, together with a significant increase of phosphorylation Smad3 (p-Smad3) (Figure 4A,B). The addition of p-Smad3 inhibitor SB431542 was shown to significantly decrease the expression of Six 2 and suppress the expression of the proliferation maker Ki67 (Figure 4C). These data verified the conclusion that the activation of the TGF $\beta$ signaling pathway could promote the expression of Six 2 both at mRNA and protein levels.

In order to identify the specific transcription factor of Six2, we analyzed the promoter sequence of Six2 (USSC) and searched the predicted transcriptional factor via PROMO version 2.0 (Universitat Politècnica de Catalunya, Barcelona, Spain) $[15,16]$. We focused on the predicted factor Smad3 (from -114 to $-124 \mathrm{bp}$ ) (TGTCTGGCGC) with the least dissimilarity (2.19\%) (Figure 4D). Meanwhile, we detected the mRNA level of Smad3 with three pairs of primer after the knockdown of T $\beta R I I$ and the result demonstrated no statistical significance (Figure 4E). The strength of TGF $\beta$ signaling in the absence of T $\beta R I I$ was assessed through the expression of $\mathrm{p}-\mathrm{Smad} 3$, and the result demonstrated that knock down of T $\beta R I I$ could decrease the expression of p-Smad3 [17] and the addition of TGF $\beta I$ factor did not result in an obvious increase of p-Smad3 (Figure 4F). Next, we conducted the luciferase assay to identify whether Smad3 could up-regulate the luciferase activity of the Six2 promoter. The result showed that $\operatorname{Smad} 3$ could markedly increase the promoter activity, which indicated that Smad 3 could promote the expression of Six 2 , and the stimulation of TGF $\beta$ I could magnify the fold change compared with the cells transfected with Smad3 but without TGF $\beta$ I stimulation (Figure 4G). Furthermore, the overexpression of Smad3 was able to increase both the mRNA and protein level of Six2 (Figure 4H,I). These data proved that Smad3 could transcriptionally regulate Six2. To detect the 
proliferation function of Smad3, we overexpressed Smad3 into the mK3 cells transfected with siT $\beta$ RII. Compared with the mK3 cells transfected with siTßRII and pcDNA3.1(+), the co-transfection of siTßRII and pcDNA3.1(+)-Smad3 was able to partially rescue the proliferation phenotype (Figure 4J,K). All the data demonstrated that Smad3 can regulate Six2 transcriptionally and partially relieve the inhibited proliferation.

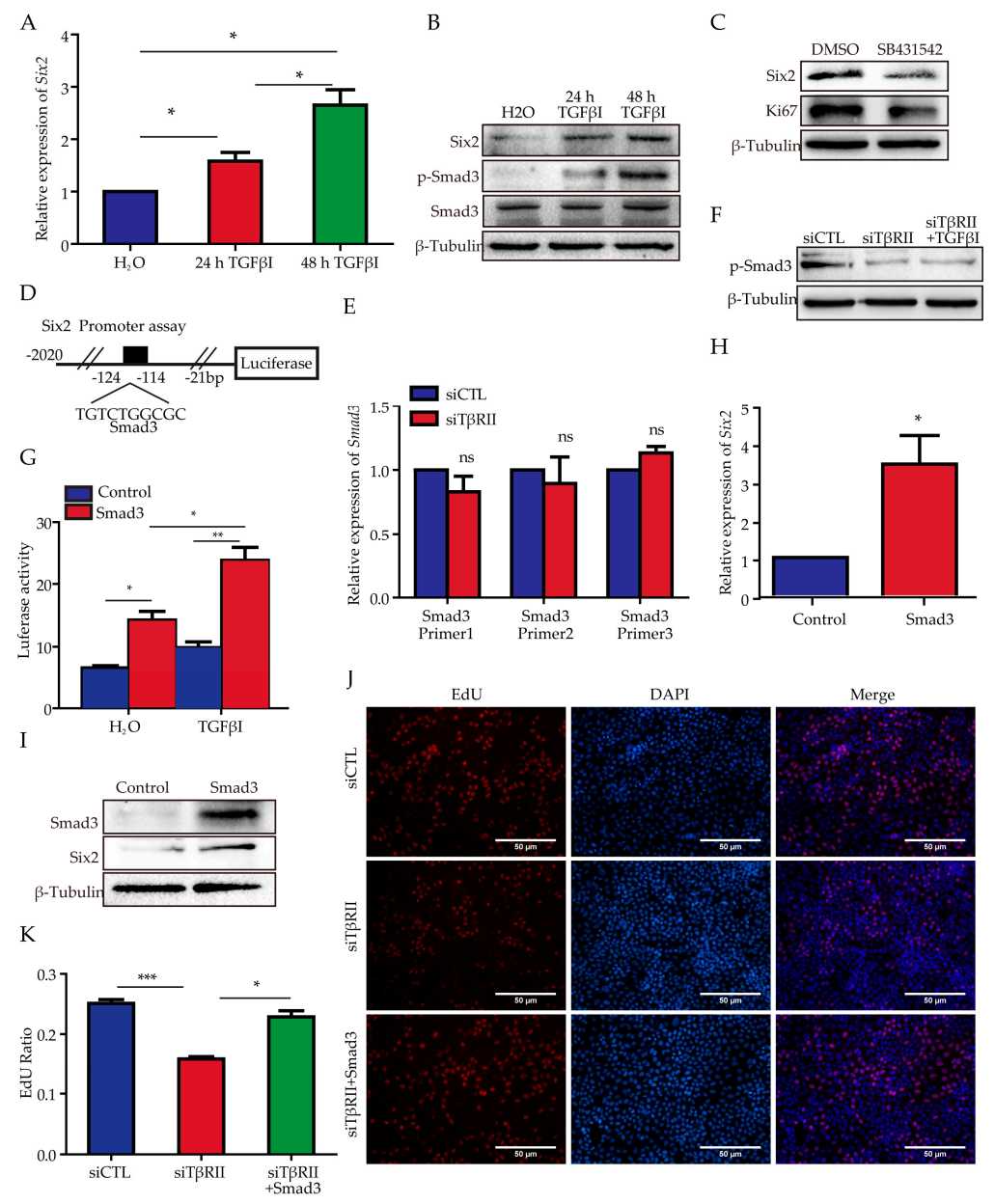

Figure 4. Smad3 transcriptionally regulates Six2 and rescues the proliferation phenotype. (A) The mRNA level of Six 2 under the time course stimulation of TGF $\beta I$ ( $2 \mathrm{ng} / \mathrm{mL})$; (B) The protein levels of Six 2 and p-Smad 3 under the time course stimulation of TGF $\beta I$ ( $2 \mathrm{ng} / \mathrm{mL})$; (C) The protein level of Six2 and Ki67 after the treatment of phosphorylation Smad3 ( p-Smad3) inhibitor SB431542 $(10 \mu \mathrm{M})$ for $48 \mathrm{~h}$; (D) The promoter analysis of Six2 via an online prediction tool (website: http://alggen.lsi.upc.es/cgi-bin/promo_v3/promo/promoinit.cgi?dirDB=TF_8.3); (E) The detection of the mRNA level of Smad3 via three pairs of primer in $\mathrm{mK} 3$ cells after the treatment of siT $\beta$ RII; (F) The protein level of $\mathrm{p}$-Smad3 with or without the stimulation of TGF $\beta \mathrm{I}(2 \mathrm{ng} / \mathrm{mL})$ for $48 \mathrm{~h}$ after the knock down of T $\beta R I I ;(G)$ pRL-SV40 and Six 2 promoter luciferase reporter together with the control vector or Smad3 under the stimulation of Tgf $\beta I(2 \mathrm{ng} / \mathrm{mL})$ for $48 \mathrm{~h}$ were transfected into HEK293 cells. After $48 \mathrm{~h}$, the cells were lysed and the fluorescences were detected and normalized to Renilla activity; (H) The mRNA level of Six2 after the overexpression of Smad3 in mK3 cells; (I) The protein level of Six 2 after the overexpression of Smad3 in mK3 cells; (J) The proliferation rate of mK3 cells after the transfection of siT $\beta$ RII and the co-transfection of Smad3; (K) Histogram shows the quantitative analysis of the EdU assay above; $(\mathbf{K})$ The proliferation rate of $\mathrm{mK} 3$ cells after the transfection of siT $\beta$ RII and the co-transfection of Smad3. All data are displayed as means \pm SD from three independent experiments. ${ }^{*} p<0.05,{ }^{* *} p<0.01,{ }^{* * *} p<0.001$. 


\section{Discussions}

The development of kidney must balance the maintenance of renal progenitor cells (cap mesenchyme) and their differentiation into components of the mature nephron, the molecular mechanism of which is the opposing actions of $\beta$-catenin and Six2 in cap mesenchyme. Six2, the pluripotent renal cell regulator, plays a crucial role in maintaining the self-renew of cap mesenchymal cells, and deletion of Six2 will disrupt the balance of nephron progenitors between self-renew and differentiation $[5,6,18]$. These research studies implied that the research of the upstream regulatory factor towards Six 2 is of great importance. According to the limited associated reports, the miR181 family is able directly target the 3'UTR of Six2 and suppress its expression [18,19], Recombination signal binding protein for immunoglobulin kappa J region (Rbpj) is sufficient for the down-regulation of Six2 [20], Notch2 can shut down the Six2 mediated program for progenitor maintenance [21], and Pax2/Eya1/Hox11 complex binds to the proximal promoter of Six2 and thus regulates its expression [22].

Recently, TßRII was shown to have a similar expression pattern with Six2, the crucial transcriptional factor maintaining the self-renewal of the cap mesenchyme, between cap mesenchyme $(\mathrm{CM})$ and the renal vesicles (RVs). To define the effect and underlying mechanism of T $\beta$ RII during kidney development specifically, we inhibited the expression of T $\beta R I I$ via siRNA in $\mathrm{mK} 3$ cell line and found that TRRII promoted the proliferation of $\mathrm{mK} 3$ cells and Six 2 expression, which can be rescued by Six 2 overexpression. Further bioinformatics analysis predicted the putative binding sites of Smad 3 in the promoter region of Six2. A subsequent luciferase assay verified that Smad3 could transcriptionally target Six2. Furthermore, the role of Smad3 in the TGF $\beta$ signaling pathway in mK3 cells was also confirmed by the rescue assay of $\mathrm{mK} 3$ cells' proliferation experiment.

\section{Materials and Methods}

\subsection{Cell Culture and Transfection}

Human Embryonic Kidney 293 (HEK293) and mK3 cells were cultured in Dulbecco's Modified Eagle's Medium (DMEM)(Gibco, Carls-bad, CA, USA) supplemented with $10 \%$ fetal bovine serum (Gemini, Shanghai, China), penicillin, and streptomycin (Gibco) at $37{ }^{\circ} \mathrm{C}, 5 \% \mathrm{CO}_{2}$, and $100 \%$ humidity. All the plasmids and siRNA (GenePharma, Shanghai, China) (the sequence is listed in Table S1) were transfected via Lipofectamine ${ }^{\mathrm{TM}} 2000$ (Invitrogen, Carlsbad, CA, USA) according to the manufacturer's instructions.

\subsection{Plasmid Construction}

The coding sequence (CDS) of Six2 was amplified via polymerase chain reaction (PCR) from the cDNA of mK3 cells and cloned at the site of BamHI and EcoRI to generate pcDNA3.1(+)-Six2. The CDS of Smad3 was amplified via PCR from HEK293 cells and cloned into pcDNA3.1(+). The promoter of Six 2 was amplified from C57BL/ 6 genomic DNA and inserted into the upstream of luciferase coding sequence of pcDNA3.1-luciferase reporter vector. The primer information is provided in Table S2.

\subsection{Luciferase Reporter Assay}

Luciferase reporter assays were performed as previously described [18].

\subsection{Collection of Embryo Kidney}

The morning of the discovery of the vaginal plug was considered as E0.5. We waited until E11.5, E12.5, E13.5, and E14.5, collected the kidneys of these embryos, and stored them at $-80^{\circ} \mathrm{C}$. 


\subsection{Real-time Polymerase Chain Reaction (PCR)}

Total embryo kidney RNA and mK3 cellular RNA were extracted with TRIzol (Invitrogen) and the RNA was reverse-transcribed using the First-Strand cDNA Synthesis kit (Thermo Scientific, Walham, MA, USA) following the manufacturer's instructions. The quantitative PCR reactions were conducted using UltraSYBR Mixture (CWBIO, Guangzhou, China). The expression levels of Six2, Smad3, and TRRII were normalized to that of $18 \mathrm{~s}$. The primers used are listed in Table S2.

\subsection{Western Blot}

The mK3 cells were collected $48 \mathrm{~h}$ after the transfection. The proteins were extracted following the process as previously described [18]. The membranes were incubated with primary antibodies (mouse anti- $\beta$-Tubulin (1:2000 dilution, Cell Signaling Technology, Beverly, MA, USA); rabbit anti-Six2 (1:1000 dilution, Proteintech, Wuhan, China); rabbit anti-T $\beta$ RII (1:300 dilution, Boster, Wuhan, China); rabbit anti-T $\beta R I$ (1:500 dilution, Proteintech); rabbit anti-Smad3 (Cell Signaling Technology); rabbit anti-p-Smad3 (Abcam, Cambridge, MA, USA) at $4{ }^{\circ} \mathrm{C}$ overnight. The secondary antibodies were goat anti-rabbit Immunoglobulin G (IgG) and goat anti-mouse IgG (1:5000 dilution, Proteintech). The final signals were developed by Chemiluminescent Horseradish Peroxidase (HRP) Substrate Reagent (Millipore, Billerica, MA, USA) and were detected with ChemiDoc ${ }^{\mathrm{TM}}$ XRS+ (Bio-Rad, Hercules, CA, USA).

\subsection{Drug Stimulation}

The mK3 cells and HEK 293 cells were treated with TGF $\beta$ I factor (Novoprotein, Shanghai, China) (dissolved in sterile double distilled $\mathrm{H}_{2} \mathrm{O}\left(\mathrm{ddH}_{2} \mathrm{O}\right)$ ) with the final concentration of $2 \mathrm{ng} / \mathrm{mL}$ for $24 \mathrm{~h}$ or $48 \mathrm{~h}$. The mK3 cells were treated with SB431542 (MedChem Express, Monmouth Junction, NJ, USA) (dissolved in sterile Dimethylsulfoxide (DMSO)) with the final concentration of $10 \mu \mathrm{M}$ for $48 \mathrm{~h}$.

\subsection{Immunofluorescence}

Forty-eight hours after the transfection, the $\mathrm{mK} 3$ cells were fixed with $4 \%$ paraformaldehyde at room temperature for $20 \mathrm{~min}$, then washed with Phosphate Buffer Solution (PBS) for $5 \mathrm{~min}$ three times and blocked with $10 \%$ goat serum with $0.1 \%$ Triton X-100 in PBS at room temperature for $1 \mathrm{~h}$. Afterwards, the cells were incubated with the primary antibody (rabbit anti-Six2, 1:100 dilution, Proteintech) at $4{ }^{\circ} \mathrm{C}$ overnight. The cells were washed three times with PBS for $5 \mathrm{~min}$ and incubated with the secondary antibody (goat anti-rabbit FITC, 1:500 dilution, Invitrogen) at room temperature for $1 \mathrm{~h}$ away from light. Next, they were dyed with 4',6-diamidino-2-phenylindole (DAPI) for $10 \mathrm{~min}$ at room temperature. The map was detected by fluorescence microscopy.

\subsection{EdU Cell Proliferation Assay}

5-Ethynyl-2'-deoxyuridine (EdU) assay was conducted to detect the cell proliferation. Forty-eight hours after transfection, the proliferation experiment of the mK3 cells was performed with Cell-Light EdU Apollo 567 In Vitro Kit (RiboBio Co., Ltd., Guangzhou, China) according to the manufacturer's instructions. The final proliferation rate of $\mathrm{mK} 3$ cells was determined by the ratio of EdU-staining-positive cells (red) to the total cell number labelled by DAPI (blue).

\subsection{Statistical Analysis}

The software of GraphPad Prism 5 (GraphPad Software, Inc., La Jolla, CA, USA) was used to analyze all the data. All data were collected from at least three independent experiments. The results were shown as means $\pm \mathrm{SD}$ with $p<0.05$ considered statistically significant. 


\section{Conclusions}

Taken together, our research described four important findings (Figure 5): (1) That knockdown of T $\beta$ RII could inhibit the proliferation of $\mathrm{mK} 3$ cells; (2) that the expression of Six 2 was inhibited after the knockdown of T $\beta$ RII; (3) that T $\beta$ RII regulated the proliferation of MM cells through Six2; (4) that the activation of the TGF $\beta$ signaling pathway increased the expression of Six2; (5) that T $\beta$ RII regulated Six 2 through the transcriptional regulation of Smad3. This mechanism was observed in the $\mathrm{mK} 3$ cells, and the specific role of T $\beta$ RII in early kidney development in vitro was verified by Six 2 . Given the critical role of T $\beta$ RII in early kidney development, we will continue to explore whether $\mathrm{T} \beta \mathrm{RII}$ can affect the embryonic kidney development in vivo. The insights from the recent and ongoing studies could potentially lead to the confirmation of the specific role of TGF $\beta$ and T $\beta$ RII in early kidney development.

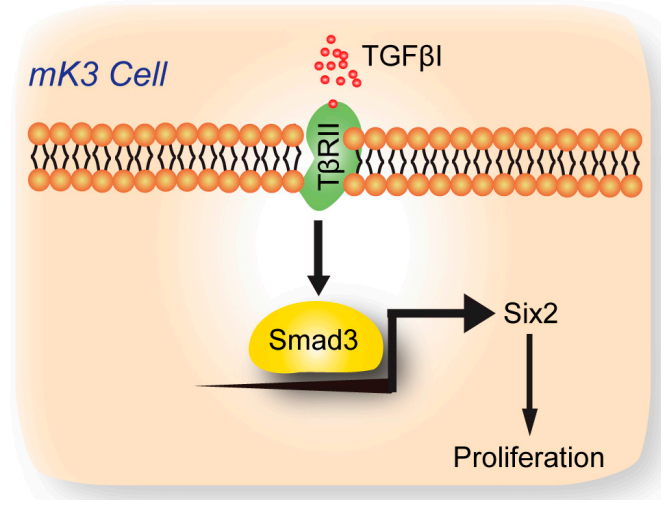

Figure 5. A schematic diagram of the molecular mechanism that T $\beta$ RII promotes the proliferation of metanephric mesenchyme (MM) cells.

Supplementary Materials: Supplementary materials can be found at www.mdpi.com/1422-0067/18/4/853/s1.

Acknowledgments: This work was supported by the National Natural Science Foundation of China (grants 81572076 and 31271563) and the National Natural Science Foundation of China (grant no. 31200971).

Author Contributions: Zhaomin Mao designed and performed the experiments and also wrote the paper; Zhongshi Lyu designed and performed the experiments; Liyuan Huang performed part of the experiments; Qin Zhou read the paper; Yaguang Weng conceived, designed and wrote the paper.

Conflicts of Interest: The authors declare no conflict of interest.

\section{References}

1. Massague, J. TGF $\beta$ signalling in context. Nat. Rev. Mol. Cell Biol. 2012, 13, 616-630. [CrossRef] [PubMed]

2. Nakao, A.; Afrakhte, M.; Moren, A.; Nakayama, T.; Christian, J.L.; Heuchel, R.; Itoh, S.; Kawabata, M.; Heldin, N.E.; Heldin, C.H.; et al. Identification of Smad7, a TGF $\beta$-inducible antagonist of TGF- $\beta$ signalling. Nature 1997, 389, 631-635. [PubMed]

3. Little, M.H.; McMahon, A.P. Mammalian kidney development: Principles, progress, and projections. Cold Spring Harb. Perspect. Biol. 2012, 4. [CrossRef] [PubMed]

4. Celeste Kusaba, T.; Lalli, M.; Kramann, R.; Kobayashi, A.; Humphreys, B.D. Differentiated kidney epithelial cells repair injured proximal tubule. Proc. Natl. Acad. Sci. USA 2014, 111, 1527-1532. [CrossRef] [PubMed]

5. Self, M.; Lagutin, O.V.; Bowling, B.; Hendrix, J.; Cai, Y.; Dressler, G.R.; Oliver, G. Six2 is required for suppression of nephrogenesis and progenitor renewal in the developing kidney. EMBO J. 2006, 25, 5214-5228. [CrossRef] [PubMed]

6. Kobayashi, A.; Valerius, M.T.; Mugford, J.W.; Carroll, T.J.; Self, M.; Oliver, G.; McMahon, A.P. Six2 defines and regulates a multipotent self-renewing nephron progenitor population throughout mammalian kidney development. Cell Stem Cell 2008, 3, 169-181. [CrossRef] [PubMed] 
7. Karner, C.M.; Das, A.; Ma, Z.; Self, M.; Chen, C.; Lum, L.; Oliver, G.; Carroll, T.J. Canonical Wnt9b signaling balances progenitor cell expansion and differentiation during kidney development. Development 2011, 138, 1247-1257. [CrossRef] [PubMed]

8. Park, J.S.; Ma, W.; O’Brien, L.L.; Chung, E.; Guo, J.J.; Cheng, J.G.; Valerius, M.T.; McMahon, J.A.; Wong, W.H.; McMahon, A.P. Six2 and Wnt regulate self-renewal and commitment of nephron progenitors through shared gene regulatory networks. Dev. Cell 2012, 23, 637-651. [CrossRef] [PubMed]

9. Das, A.; Tanigawa, S.; Karner, C.M.; Xin, M.; Lum, L.; Chen, C.; Olson, E.N.; Perantoni, A.O.; Carroll, T.J. Stromal-epithelial crosstalk regulates kidney progenitor cell differentiation. Nat. Cell Biol. 2013, 15, 1035-1044. [CrossRef] [PubMed]

10. Stark, K.; Vainio, S.; Vassileva, G.; McMahon, A.P. Epithelial transformation of metanephric mesenchyme in the developing kidney regulated by Wnt-4. Nature 1994, 372, 679-683. [CrossRef] [PubMed]

11. Kispert, A.; Vainio, S.; McMahon, A.P. Wnt-4 is a mesenchymal signal for epithelial transformation of metanephric mesenchyme in the developing kidney. Development 1998, 125, 4225-4234. [PubMed]

12. Reidy, K.J.; Rosenblum, N.D. Cell and molecular biology of kidney development. Semin. Nephrol. 2009, 29, 321-337. [CrossRef] [PubMed]

13. Brunskill, E.W.; Potter, S.S. RNA-Seq defines novel genes, RNA processing patterns and enhancer maps for the early stages of nephrogenesis: Hox supergenes. Dev. Biol. 2012, 368, 4-17. [CrossRef] [PubMed]

14. Valerius, M.T.; Patterson, L.T.; Witte, D.P.; Potter, S.S. Microarray analysis of novel cell lines representing two stages of metanephric mesenchyme differentiation. Mech. Dev. 2002, 110, 151-164. [CrossRef]

15. Messeguer, X.; Escudero, R.; Farre, D.; Nunez, O.; Martinez, J.; Alba, M.M. PROMO: Detection of known transcription regulatory elements using species-tailored searches. Bioinformatics 2002, 18, 333-334. [CrossRef] [PubMed]

16. Farre, D.; Roset, R.; Huerta, M.; Adsuara, J.E.; Rosello, L.; Alba, M.M.; Messeguer, X. Identification of patterns in biological sequences at the ALGGEN server: PROMO and MALGEN. Nucleic Acids Res. 2003, 31, 3651-3653. [CrossRef] [PubMed]

17. Gewin, L.; Vadivelu, S.; Neelisetty, S.; Srichai, M.B.; Paueksakon, P.; Pozzi, A.; Harris, R.C.; Zent, R. Deleting the TGF- $\beta$ receptor attenuates acute proximal tubule injury. J. Am. Soc. Nephrol. 2012, 23, 2001-2011. [CrossRef] [PubMed]

18. Mao, Z.; Wang, H.; Fang, Y.; Chen, T.; Wan, Q.; Wang, M.; Wang, N.; Xiao, J.; Wei, H.; Li, X.; et al. MiR-181b targets Six 2 and inhibits the proliferation of metanephric mesenchymal cells in vitro. Biochem. Biophys. Res. Commun. 2013, 440, 495-501.

19. Lv, X.; Mao, Z.; Lyu, Z.; Zhang, P.; Zhan, A.; Wang, J.; Yang, H.; Li, M.; Wang, H.; Wan, Q.; et al. miR181c promotes apoptosis and suppresses proliferation of metanephric mesenchyme cells by targeting Six 2 in vitro. Cell Biochem. Funct. 2014, 32, 571-579. [CrossRef] [PubMed]

20. Chung, E.; Deacon, P.; Marable, S.; Shin, J.; Park, J.S. Notch signaling promotes nephrogenesis by downregulating Six2. Development 2016, 143, 3907-3913. [CrossRef] [PubMed]

21. Fujimura, S.; Jiang, Q.; Kobayashi, C.; Nishinakamura, R. Notch2 activation in the embryonic kidney depletes nephron progenitors. J. Am. Soc. Nephrol. 2010, 21, 803-810. [CrossRef] [PubMed]

22. Gong, K.Q.; Yallowitz, A.R.; Sun, H.; Dressler, G.R.; Wellik, D.M. A Hox-Eya-Pax complex regulates early kidney developmental gene expression. Mol. Cell. Biol. 2007, 27, 7661-7668. [CrossRef] [PubMed]

(C) 2017 by the authors. Licensee MDPI, Basel, Switzerland. This article is an open access article distributed under the terms and conditions of the Creative Commons Attribution (CC BY) license (http://creativecommons.org/licenses/by/4.0/). 